\title{
Vibrational Spectra and Structural Considerations of Compounds $\mathrm{NaLnTiO}_{4}$
}

\author{
G. BLASSE AND G. P. M. VAN DEN HEUVEL
}

Solid State Department, Physical Laboratory, State University, Utrecht, The Netherlands

Received June 7, 1973

\begin{abstract}
The Raman and infrared spectra of compounds $\mathrm{NaLnTiO}_{4}(\mathrm{Ln}=$ lanthanide, including yttrium) are reported and discussed. Their most striking feature is a strong band in both spectra at about $900 \mathrm{~cm}^{-1}$. This band is ascribed to a vibration localized in the Ti-O bond directed towards the $\mathrm{Na}-\mathrm{O}$ layers. The relevant oxygen anion is very poorly charge compensatcd, and the $\mathrm{Ti}-\mathrm{O}$ bond is, therefore, very strong. Pauling's electrostatic valence rule appears to be of great use in these considerations. These compounds do not show ferroelectricity.
\end{abstract}

\section{Introduction}

Some years ago one of us described the structure of a new series of compounds $\mathrm{NaLnTiO}_{4} \quad(\mathrm{Ln}=$ lanthanide, $\quad$ including yttrium) (l). This structure can be derived from the $\mathrm{K}_{2} \mathrm{NiF}_{4}$ structure by ordering the

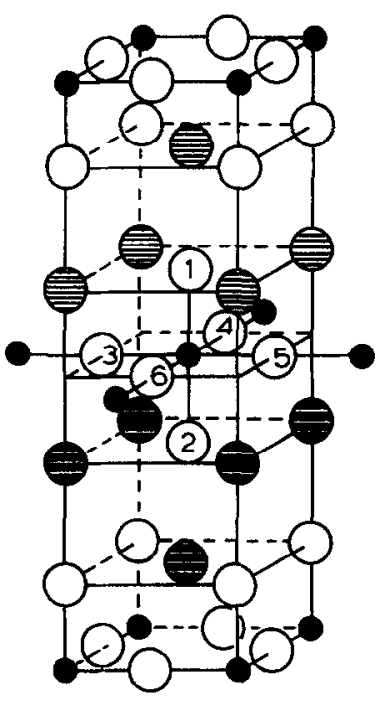

Fir. 1. Crystal structure of $\mathrm{NaLnTiO}_{4}$. Black ions, $\mathrm{Ti}^{4+}$; white ions, $\mathrm{O}^{2-}$; ions hatched with thin lines, $\mathrm{Na}^{+}$; ions hatched with thick lines, $\mathrm{Ln}^{3+}$.

Copyright (C) 1974 by Academic Press, Inc. All rights of reproduction in any form reserved. Printed in Great Britain
$\mathrm{Na}^{+}$and $\mathrm{Ln}^{3+}$ ions among the larger cation sites. This superstructure is remarkable because there are double layers of $\mathrm{Ln}^{3+}$ ions and double layers of $\mathrm{Na}^{+}$ions perpendicular to the $c$ axis (Fig. 1). As a consequence, a poor charge compensation between the titanate layers occurs. This structure was confirmed by a study of the luminescene of trivalent lanthanide ions in compounds $\mathrm{NaLnTiO}_{4}$ (2).

In the course of our studies on the vibrational spectra of solid tungstates, niobates, titanates, etc. (3), we became again interested in the compounds $\mathrm{NaLnTiO}_{4}$. Last (3) has given a site group analysis of the infrared spectra of titanates with perovskite structure assigning two strong absorption bands to the $v_{3}$ and $v_{4}$ mode of the $\mathrm{TiO}_{6}$ octahedron. The Raman spectrum of a.o. $\mathrm{Sr}_{2} \mathrm{TiO}_{4}$ has been given in Ref. (4) together with a factor group analysis. A complete site group analysis of the $\mathrm{TiO}_{6}$ octahedron in solids was possible for $\mathrm{La}_{2} \mathrm{MgTiO}_{6}$ (5). This compound has ordered perovskite structure with one undistorted $\mathrm{TiO}_{6}$ octahedron per primitive cell. The following assignment was made: $v_{1}$, $725 \mathrm{~cm}^{-1} ; v_{3}, 600 \mathrm{~cm}^{-1} ; v_{4}, 460$ and $412 \mathrm{~cm}^{-1}$; $v_{5}, 487$ and $499 \mathrm{~cm}^{-1}$.

It is the aim of the present paper to investigate the vibrational spectra of the compounds 


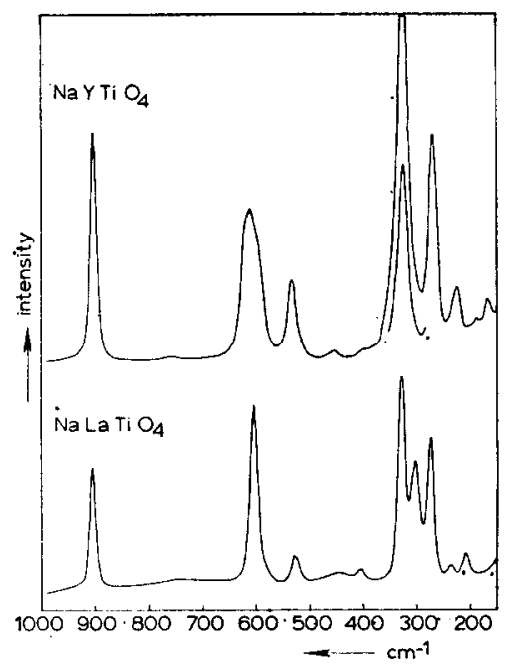

FIG. 2. Raman spectra of $\mathrm{NaLaTiO}_{4}$ and $\mathrm{NaYTiO}_{4}$.

$\mathrm{NaLnTiO}_{4}$ and to compare the results with those for $\mathrm{La}_{2} \mathrm{MgTiO}_{6}$ with regular $\mathrm{TiO}_{6}$ octahedra that do not have oxygen ions in common and with those for $\mathrm{Sr}_{2} \mathrm{TiO}_{4}$ to investigate the influence of the order of the $\mathrm{Na}^{+}$ and $\mathrm{Ln}^{3+}$ ions on the $\mathrm{Sr}^{2+}$ sublattice of $\mathrm{Sr}_{2}$ $\mathrm{TiO}_{4}$. This influence was found to be very profound.

\section{Experimental}

Samples were prepared as described earlier (1). They were checked by $\mathrm{X}$-ray analysis using $\mathrm{Cu} K \alpha$ radiation. The way in which the vibrational spectra were obtained has been described previously (5). All measurements were performed at room temperature.

\section{Results}

Figure 2 gives the Raman spectra of $\mathrm{NaLa}$ $\mathrm{TiO}_{4}$ and $\mathrm{NaYTiO}_{4}$. Figure 3 presents the infrared spectrum of $\mathrm{NaYTiO}_{4}$. Table I tabulates other spectra.

\section{Discussion}

We start with a factor group analysis. For $\mathrm{Sr}_{2} \mathrm{TiO}_{4}$ (space group $D_{4 h}^{17}$ ) the following vibrational modes are expected: $2 A_{1 g}+$

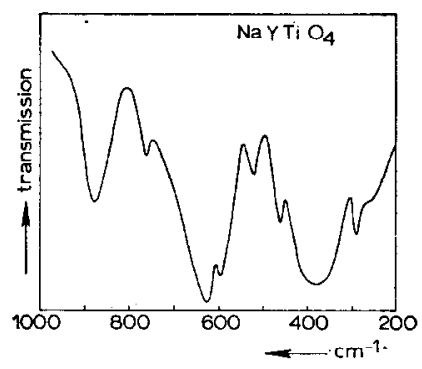

Fig. 3. Infrared spectrum of $\mathrm{NaYTiO}_{4}$.

$2 E_{g}+3 A_{2 u}+B_{2 u}+4 E_{u}$, yielding 4 Ramanactive modes and 7 infrared-active modes. Experimentally 3 strong and 6 much weaker Raman lines have been observed (4) and 6 infrared bands (Table 1). This agrees reasonably with the expected numbers. For $\mathrm{NaLnTiO}_{4}$ (space group $C_{4 v}^{1}$ ) the situation is more complicated, since this space group is not body-centered as in the case of $D_{4 h}^{17}$. The number of modes is therefore higher: $11 A_{1}+2 B_{1}+13 E$. In view of this, we expect 26 Raman-active modes and 24 infraredactive modes.

TABLE I

Vibrational Spectra of Some of the Compounds Studied (All VAlues IN $\mathrm{cm}^{-1}$ )

\begin{tabular}{|c|c|c|c|c|}
\hline & \multirow{2}{*}{$\underset{\text { IR }}{\mathrm{NaLaTiO}_{4}}$} & \multicolumn{2}{|c|}{$\mathrm{NaGdTiO}_{4}$} & \multirow{2}{*}{$\begin{array}{c}\mathrm{Sr}_{2} \mathrm{TiO}_{4} \\
\text { IR }\end{array}$} \\
\hline & & IR & $\mathbf{R}$ & \\
\hline \multirow[t]{3}{*}{$v_{1}$} & 890 & 880 & 905 & \\
\hline & & 760 & 770 & \\
\hline & & 625 & & 585 \\
\hline$v_{3}$ & 610 & $600(s h)$ & 620 & $525(s h)$ \\
\hline \multirow[t]{2}{*}{$v_{s}(?)$} & 535 & 520 & 535 & 180 \\
\hline & & $430(s h)$ & 455 & \\
\hline \multirow[t]{3}{*}{$v_{4}$} & 375 & 385 & $\begin{array}{l}345 \\
320\end{array}$ & 370 \\
\hline & 280 & 290 & 270 & $\sim 300(s h)$ \\
\hline & 220 & 230 & $\begin{array}{l}240 \\
220\end{array}$ & 235 \\
\hline
\end{tabular}

${ }^{a} \mathbf{R}$, Raman spectrum IR, infrared spectrum 
Such large numbers are not observed, however. Counting even weak lines and bands, the total number of modes observed experimentally is about half the number predicted from a factor group analysis.

This seems to indicate that the influence of the superstructure at the larger cation sublattice is not profound. A superficial comparison between the vibrational spectra of $\mathrm{NaLnTiO}_{4}$ and $\mathrm{Sr}_{2} \mathrm{TiO}_{4}$ reveals that this cannot be true. The spectra of the compounds $\mathrm{NaLnTiO}_{4}$ contain a strong band at about $900 \mathrm{~cm}^{-1}$. This band is absent in $\mathrm{Sr}_{2} \mathrm{TiO}_{4}$. In view of its spectral position this band can only be due to a $\mathrm{Ti} \mathrm{O}$ vibrational mode. The fact that this mode is observed at relatively high wavenumbers must be connected with the superstructure on the larger cation lattice.

Since factor group analysis is not very promising to investigate this phenomenon further, we tried the internal mode approach. Let us consider the $\mathrm{TiO}_{6}$ octahedron in $\mathrm{NaLn}$ $\mathrm{TiO}_{4}$ as a molecular group with internal modes in which the other lattice constituants do not participate in first approximation. The site symmetry of the $\mathrm{TiO}_{6}$ octahedron is $C_{4 v}$ (see Fig. 1). Table II gives the vibrational modes to be expected in comparison with those for a regular octahedron. We will now discuss where the internal modes of the $\mathrm{TiO}_{6}$ octahedron can be expected:

$v_{1}$. This symmetrical stretching mode has been observed in the Raman spectrum of

\section{TABLE II}

SElection Rules for Vibrational Modes of aN OctaHedral Group UNDER $O_{h}$ AND $C_{4 v}$ Symmetry ${ }^{a}$

\begin{tabular}{lll}
\hline & \multicolumn{2}{c}{ Representation } \\
\cline { 2 - 3 } Mode & \multicolumn{1}{c}{$O_{h}$} & \multicolumn{1}{c}{$C_{4 v}$} \\
\hline & & \\
$v_{1}$ & $A_{1 g}(\mathrm{R})$ & $A_{1}(\mathrm{R}, \mathrm{IR})$ \\
$v_{2}$ & $E_{g}(\mathrm{R})$ & $A_{1}(\mathrm{R}, \mathrm{IR})+B_{1}(\mathrm{R})$ \\
$v_{3}, v_{4}$ & $T_{1 u}(\mathrm{IR})$ & $A_{1}+E(\mathrm{both} \mathrm{R}, \mathrm{IR})$ \\
$v_{5}$ & $T_{2 g}(\mathrm{R})$ & $B_{2}(\mathrm{R})+E(\mathrm{R}, \mathrm{IR})$ \\
\hline
\end{tabular}

a $\mathbf{R}$, Raman active; IR, infrared active.
$\mathrm{La}_{2} \mathrm{MgTiO}_{6}$ at $725 \mathrm{~cm}^{-1}(5)$. The strong band in the Raman and infrared spectra at about $900 \mathrm{~cm}^{-1}$ in the case of $\mathrm{NaLnTiO}_{4}$ must be due to $v_{1}$. It is situated at very high wavenumbers. Its strong intensity in the infrared spectrum where it is completely forbidden for a. regular octahedron indicates a strong deviation from cubic symmetry. We will try to explain the peculiar behavior of the $v_{1}$ mode in $\mathrm{NaLnTiO}_{4}$ below.

$v_{3}$ and $v_{4}$. These modes (asymmetrical stretching and bending, respectively) are always observed as strong absorption bands in the infrared in the case of titanate perovskites or related compounds: in $\mathrm{La}_{2} \mathrm{MgTiO}_{6}$ at 600 and about $435 \mathrm{~cm}^{-1}(5)$, in $\mathrm{SrTiO}_{3}$ at 610 and $395 \mathrm{~cm}^{-1}(3)$, and in $\mathrm{Sr}_{2} \mathrm{TiO}_{4}$ at 585 and $370 \mathrm{~cm}^{-1}$, respectively. We, therefore, assume that the strong bands at about 610 and 375 $\mathrm{cm}^{-1}$ in the infrared spectra of $\mathrm{NaLnTiO}_{4}$ (values for $\mathbf{L n}=\mathrm{La}$ ) are essentially the $v_{3}$ and $v_{4}$ modes, respectively. In view of the $C_{4 v}$ symmetry (see Table II), a splitting is to be expected. This is observed experimentally (Table I and Fig. 3). The splitting increases in the sequence $\mathrm{La} \rightarrow \mathrm{Lu}$. It is quite plausible that the tetragonal field strength increases also in this sequence (compare Fig. 1). As a consequence, the strong Raman line at about $610 \mathrm{~cm}^{-1}$ is also assigned to the $v_{3}$ mode. Its high intensity indicates again the strong deviation from inversion symmetry.

$v_{2}$. This mode has usually extremely weak intensity (6), so that it is not discussed here.

The weak band at $760 \mathrm{~cm}^{-1}$ observed in the greater part of the spectra is at very high wavenumbers if it should correspond to $v_{2}$. Perhaps this band is an overtone of the strong infrared absorption band at $375 \mathrm{~cm}^{-1}\left(v_{3}\right)$.

$v_{5}$. In $\mathrm{La}_{2} \mathrm{MgTiO}_{6}$ this mode is observed around $495 \mathrm{~cm}^{-1}$. It is therefore tempting to ascribe the bands around $500 \mathrm{~cm}^{-1}$ to this mode.

This gives a rough and incomplete assignment of the vibrational spectra of compounds $\mathrm{NaLnTiO}_{4}$. We are left with some strong bands around $300 \mathrm{~cm}^{-1}$. These must be due to external lattice modes. In view of the ionic charges in the present compounds, these are probably located in the $\mathbf{L n}-\mathrm{O}$ layer. In this connection, it may be remarked that the compounds 
LnOCl (7) and $\mathrm{Ln}_{2} \mathrm{MoO}_{6}(8)$, which also contain $\mathrm{Ln}-\mathrm{O}$ layers with a slightly different structure, show also strong absorption in the region around $300 \mathrm{~cm}^{-1}$.

We will now try to account for the strong deviation from cubic symmetry of the $\mathrm{TiO}_{6}$ octahedron using structural arguments. For this purpose, we have numbered the oxygen ions around the $\mathrm{Ti}^{4+}$ ion as indicated in Fig. 1 . None of these oxygen ions obeys Pauling's electrostatic valence rule (9). According to this rule, the valence of each anion (in our case, 2) is exactly or nearly exactly equal to the sum of the strengths of the electrostatic bonds to it from the adjacent cations. This strength $s$ is defined as $s=z / v$, where $z e$ is the electric charge of the cation and $v$ its coordination number. For oxides, Pauling's rule reads

$$
\sum_{i} z_{i} / v_{i}=2 \text {. }
$$

For $\mathrm{O}_{1}$ in $\mathrm{NaLnTiO}_{4}$, however, the left-hand side of this equation yields only $1 \frac{2}{9}$. For $\mathrm{O}_{2}$, on the other hand, this value is much higher than 2 , viz. $2 \frac{1}{3}$. For the other $\mathrm{O}$ anions (inside the titanate layer) it is $2 \frac{2}{9}$. In the case of $\mathrm{Sr}_{2} \mathrm{TiO}_{4}$ Pauling's rule is also not satisfied $\left(\mathrm{O}_{1}\right.$ and $\mathrm{O}_{2}, 1 \frac{7}{9}$; the other $\mathrm{O}$ 's $\left.2 \frac{2}{g}\right)$. It is the order of the $\mathrm{Na}^{+}$and $\mathrm{Ln}^{3+}$ ions which yields values that are unacceptable: $1 \frac{2}{g}$ for $\mathrm{O}_{1}$ ! There is one obvious possibility to compensate the shortage of electrostatic bond strength of this anion, viz. a displacement of the $\mathrm{Ti}^{4+}$ ion from the octahedral center towards the $\mathrm{O}_{1}$ ion. As a consequence we expect that the $\mathrm{Ti}-\mathrm{O}_{1}$ bond strength is exceptionally high. The consequence of this model is that the $v_{1}$ mode situated at relatively high wavenumbers is thought of as a stretching vibration located mainly in the Ti-O $\mathrm{O}_{1}$ bond. This explains also the high intensity of $v_{1}$ in the infrared spectrum.

It is interesting to compare our value for $v_{1}$ (about $900 \mathrm{~cm}^{-1}$ ) with values observed for the $\mathrm{Ti}-\mathrm{O}$ stretching vibration in some molecular compounds. Siebert (10) states that the Ti-O bond has considerable double-bond character, if the stretching vibration lies above $800 \mathrm{~cm}^{-1}$. Dehnicke (11) gives $836 \mathrm{~cm}^{-1}$ for Ti-O stretching in $\mathrm{TiOCl}_{2}$ and $1078 \mathrm{~cm}^{-1}$ for Ti-O in $\mathrm{TiOCl}_{2} \cdot 2 \mathrm{POCl}_{3}$. He assumes that this value corresponds to a real double bond and quotes also the value for the $\mathrm{V}=\mathrm{O}$ stretching of $\mathrm{VOCl}_{3}: 1035 \mathrm{~cm}^{-1}(12)$. In $\mathrm{VOCl}_{3}$ the presence of a vanadyl group is generally accepted.

From these values we learn that our value of $900 \mathrm{~cm}^{-1}$ indicates that the $\mathrm{Ti}-\mathrm{O}_{1}$ bond is very strong. Qualitatively, it is somewhere between a single and a double bond. This occurs because of the superstructure of the $\mathrm{Na}^{+}$and $\mathrm{Ln}^{3+}$ ions which results in a poor charge compensation. It may be even anticipated that the $\mathrm{Ti}^{4+}$ ion is so strongly displaced that it must be considered as five-coordinated. In view of this, a crystal structure refinement of the compounds $\mathrm{NaLnTiO}_{4}$ is challenging, but, we ourselves are not able to perform it.

Considerations like those presented above have a more general applicability. Consider, for example, the crystal structure of $\mathrm{Gd}_{2} \mathrm{SiO}_{5}$ (13). This structure contains two types of oxygen anions: $80 \%$ belong to the $\mathrm{SiO}_{4}$ tetrahedral complex, $20 \%$ are not silicon bonded. The latter type of oxygen anions are surrounded tetrahedrally by four $\mathrm{Gd}^{3+}$ ions, three of which have seven-coordination, the fourth ninecoordination. Pauling's valence rule gives for this oxygen ion 1.62 , a value much too low. This is compensated by a short distance between the $\mathrm{Gd}^{3+}$ ions and these anions. This is comparable to the shift of the $\mathrm{Ti}^{4+}$ ion described above.

Further Felsche (14) has given a striking correlation between the individual $\mathrm{Si}-\mathrm{O}$ bond lengths in a large number of silicates and the charge balance on the oxygen ions. $\mathrm{He}$, however, used a correction on Pauling's electrostatic valence rule for the cationanion distance which seems to be quite reasonable.

Finally, we note that in none of the infrared spectra of titanates compiled in a recent publication (15) has a strong absorption around $900 \mathrm{~cm}^{-1}$ been observed, except in the case of what the authors call $\mathrm{Bi}_{2}\left(\mathrm{TiO}_{3}\right)_{2}$. In view of phase diagram studies (16), this material probably consists of mainly $\mathrm{Bi}_{4} \mathrm{Ti}_{3}$ $\mathrm{O}_{12}$. The latter compound has a layer structure consisting of perovskite-like and $\mathrm{Bi}-\mathrm{O}$ layers (17). This compound has very short $\mathrm{Ti}-\mathrm{O}$ distances in the perovskite layer $(1.75 \AA)$. These bonds might be responsible for the infrared absorption around $900 \mathrm{~cm}^{-1}$. We prepared $\mathrm{Bi}_{4} \mathrm{Ti}_{3} \mathrm{O}_{12}$ and found that its infra- 
red spectrum resembles very much the spectrum of " $\mathrm{Bi}_{2}\left(\mathrm{TiO}_{3}\right)_{2}$ ", but that the band at about $940 \mathrm{~cm}^{-1}$ is absent. The one at 810 $\mathrm{cm}^{-1}$, however, is present. The Raman spectrum shows a strong line at $855 \mathrm{~cm}^{-1}$. In addition, both spectra contain bands in the region $550-600 \mathrm{~cm}^{-1}$ (asymmetric $\mathrm{Ti}-\mathrm{O}$ stretching, $v_{3}$ ), so that those present in the region $800-850 \mathrm{~cm}^{-1}$ may be due to the Ti-O bonds with short distances.

In conclusion, we note that we did not observe ferroelectricity for these compounds, either at $300^{\circ} \mathrm{K}$ or at $77^{\circ} \mathrm{K}$.

\section{Acknowledgments}

The authors are indebted to Dr. J. H. van der Maas of this University for the performance of the Raman measurements, and to Dr. A. F. Corsmit for the test for ferroelectricity.

\section{References}

1. G. Blasse, J. Inorg. Nucl. Chem. 30, 656 (1968).

2. G. Blasse and A. Bril, J. Chem. Phys. 48, 3652 (1968).

3. J. T. LAST, Phy's. Rev. 105, 1740 (1957).

4. W. B. White and V. G. Keramidas, in "Solid State Chemistry, Proc. 5th Materials Research
Symposium" (R. S. Roth and S. J. Schneider, Jr., Eds.), p. 113, N.B.S. Special Publication 364, July 1972 .

5. G. Blasse and A. F. Corsmit, J. Solid State Chem. 6, 513 (1973).

6. A. F. Corsmit, H. E. HoefdraAd, AND G. Blasse, J. Inorg. Nucl. Chem. 34, 3401 (1972).

7. A. Rulmont, Spectrochim. Acta A28, 1287 (1972).

8. J. H. G. Bode, H. R. KUIJT, M. A. J. TH. LAHEY, AND G. BLASSE, J. Solid State Chem., 8, 114(1973),

9. L. Pauling, "The nature of the Chemical Bond," Chap. 48b, Oxford University Press, London (1952).

10. H. SIEBERT, "Anwendungen der Schwingungsspektroskopie in der anorganischen Chemie," p. 120, Springer-Verlag, Berlin (1966).

11. K. Dehnicke, Z. Anorg. Allg. Chem. 309, 266 (1961).

12. H. J. Eichroff and F. Weigel, $Z$. Anorg. Allg. Chem. 275, 267 (1954).

13. Y. I. Smolin and S. P. Tkachev, Sov. Physics Kristallogr. 14, 22 (1969).

14. J. FelsChe, Structure and Bonding 13, 99 (1973).

15. R. A. Nyquist and R. O. Kagel, "Infrared Spectra of Inorganic Compounds," spectra 100-111, Academic Press, New York (1971).

16. E. I. Speranskaya, I. S. Rez, L. V. Kozlova, V. M. Skorikov, And V. I. Slavov, Izv. Akad. Nauk SSSR Neorg. Mat. 1, 232 (1965).

17. R. E. Newnham, R. W. Wolfe, AND J. F. Dorrian, Mat. Ress. Bull. 6, 1029 (1971). 